\title{
Influence of 5 major Salmonella pathogenicity islands on NK cell depletion in mice infected with Salmonella enterica serovar Enteritidis
}

\author{
Daniela Karasova, Alena Sebkova, Hana Havlickova, Frantisek Sisak, Jiri Volf, Martin Faldyna, Petra Ondrackova, \\ Vladimir Kummer, Ivan Rychlik*
}

\begin{abstract}
Background: In this study we were interested in the colonisation and early immune response of Balb/C mice to infection with Salmonella Enteritidis and isogenic pathogenicity island free mutants.

Results: The virulence of S. Enteritidis for Balb/C mice was exclusively dependent on intact SPI-2. Infections with any of the mutants harbouring SPI-2 (including the mutant in which we left only SPI-2 but removed SPI-1, SPI-3, SPI-4 and SPI-5) resulted in fatalities, liver injures and NK cell depletion from the spleen. The infection was of minimal influence on counts of splenic CD4 CD8 T lymphocytes and $\gamma \delta$ T-lymphocytes although a reduced ability of splenic lymphocytes to respond to non-specific mitogens indicated general immunosuppression in mice infected with SPI-2 positive S. Enteritidis mutants. Further investigations showed that NK cells were depleted also in blood but not in the caecal lamina propria. However, NK cell depletion was not directly associated with the presence of SPI-2 and was rather an indicator of virulence or avirulence of a particular mutant because the depletion was not observed in mice infected with other attenuated mutants such as lon and rfaL.

Conclusions: The virulence of S. Enteritidis for Balb/C mice is exclusively dependent on the presence of SPI- 2 in its genome, and a major hallmark of the infection in terms of early changes in lymphocyte populations is the depletion of NK cells in spleen and blood. The decrease of NK cells in circulation can be used as a marker of attenuation of $S$. Enteritidis mutants for Balb/C mice.
\end{abstract}

\section{Background}

Salmonella enterica serovar Enteritidis ( $S$. Enteritidis) is one of the major causative agents of human food borne diseases. Besides humans, S. Enteritidis is frequently associated with poultry but may be isolated also from pigs, cattle as well as different reptiles. If mice are infected experimentally, especially the highly susceptible Nramp-defective Balb/C lineage, $S$. Enteritidis causes a disease similar to that caused by $S$. Typhimurium. To successfully colonise such a broad range of different hosts, $S$. Enteritidis has acquired genes which are frequently clustered at particular parts of chromosome called Salmonella Pathogenicity Islands (SPI). Although there are up to 14 different pathogenicity islands, the presence of which varies among different serovars of

\footnotetext{
* Correspondence: rychlik@vri.cz

Veterinary Research Institute, Hudcova 70, 62100 Brno, Czech Republic
}

Salmonella enterica (S. enterica), 5 of these can be found in all $S$. enterica serovars.

The SPI-1 and SPI-2 pathogenicity islands are considered as the most important for S. enterica virulence. Proteins encoded by SPI-1 form a type III secretion system (TTSS) which mediates the translocation of $S$. enterica proteins into a host cell across its cytoplasmic membrane. The translocated proteins induce cytoskeletal rearrangements which results in S. enterica uptake even by non-professional phagocytes [1,2]. Genes localised within SPI-2 encode proteins of another TTSS expressed by $S$. enterica inside host cells where it translocates its proteins across the phagosomal membrane and increases intracellular survival [3]. The functions of the genes localised on the remaining SPIs are less well characterised; for SPI-3 genes conflicting information has been published suggesting their role both in gut colonisation and intracellular survival $[4,5]$. SPI-4 genes 
are required for the intestinal phase of disease [5] although a SPI-4 requirement for systemic infection of mice has been also reported [6]. Genes localised at SPI5 are co-regulated with either SPI- 1 or SPI- 2 genes and therefore represent a dually controlled system $[7,8]$.

After oral ingestion, S. enterica comes into contact with the intestinal epithelial lining and using the SPI-1 encoded TTSS it enters M-cells and enterocytes. After crossing the epithelium $S$. enterica interacts with neutrophils and macrophages. The result of these initial events is critical for the outcome of the disease. If S. enterica is not recognised by host cells, and the proinflammatory immune response in the gut is not induced, it is likely that the infection will develop into a typhoid-like disease [9-11]. During the course of the typhoid-like infection of mice, $S$. enterica colonises internal organs such as liver and spleen where it is found in macrophages, neutrophils, and T- and B-lymphocytes [12]. Why the immune system of a host does not respond properly to S. enterica infection during the typhoid disease has never been explained in sufficient detail although it is known that $S$. enterica is capable of induction of apoptosis in macrophages $[13,14]$, inhibition of antigen presentation by dendritic cells [15] and also NK cell depletion [16].

Except for the role of SPI-1 in invasiveness the nonprofessional phagocytes and SPI-2 in intracellular survival, roles of the remaining 3 major pathogenicity islands in the interactions of $S$. enterica with host immune system are not too much elucidated. In this study we therefore removed the 5 major pathogenicity islands from the $S$. Enteritidis genome in a step-by-step manner and used such mutants for oral infection of Balb/C mice. We found out that virulence in mice was exclusively dependent on SPI-2 because even the mutant in which SPI-1, SPI-3, SPI-4 and SPI-5 pathogenicity islands had been removed from its genome was as virulent as the wild type strain. When the changes in splenic lymphocytes were determined 5 days post infection, Blymphocytes, CD8 and $\gamma \delta$ T-lymphocytes did not change regardless of the mutant used for the infection. The only lymphocyte population which decreased in the spleen and blood after the infection with virulent $S$. Enteritidis, but not the attenuated mutants, was formed by NK cells.

\section{Results}

Mice infected with the wild-type $S$. Enteritidis or any of the mutants harboring SPI-2 died within 3 weeks postinfection whereas all mice infected with any of the mutants not possessing SPI-2 survived the infection (Figure 1). Mice infected with mutants harboring SPI-2 in their genome exhibited high counts of $S$. Enteritidis in liver and spleen at day 5 post infection (Table 1). Histological examination did not reveal any difference in the caecum in the animals while necrotic foci were observed in the livers of mice infected with the wild type $S$. Enteritidis or the mutants harboring SPI-2 (Figure 2). As a result of these observations, in some of the data analyses described below, we clustered the strains into two groups, SPI-2 positive and SPI-2 negative, regardless of the presence or absence of additional pathogenicity islands.

Next we were interested to what extent the different virulence of individual SPI mutants would be reflected in host immune responses. Since the cell-mediated immune response is important for the protection against $S$. enterica and lymphocytes play an important role in the co-ordination of the host's immune response, we first characterised changes in lymphocyte subpopulations after the infection with the wild type strain and all the SPI mutants. When 3 mice from each group were sacrificed on day 5 post infection i.e. before the onset of fatalities, no differences in the distribution of splenic Blymphocytes, CD3 T-lymphocytes and $\gamma \delta$ T-lymphocytes were observed. Of the Th lymphocytes, the only statistically significant change was the decrease in number of CD4 lymphocytes observed after the infection with the SPI2o mutant when compared with the non-infected mice. CD4 lymphocytes also decreased in number after the infection with the $\triangle$ SPI1 mutant, i.e. another mutant in which, similarly to the SPI2o mutant, SPI-1 was absent while SPI-2 was present, although in this case the decrease did not reach statistical significance $(\mathrm{P}=$ 0.0634 , see also Table 2). However, we did not investigate this further because we found another lymphocyte subpopulation which exhibited a more pronounced changes which also correlated with the severity of the infection (see below).

Although the T- and B-lymphocytes did not change in their relative counts in the spleens of infected mice, we observed that the lymphocytes from mice infected with SPI-2 positive mutants were suppressed in their response to non-specific mitogens. Due to the limited number of mice in individual groups this difference was not significant when individual groups of mice were compared with the non-infected controls. However, when the mice were grouped according to their virulence i.e. according to the presence or absence of SPI-2, all SPI-2 positive virulent strains induced significant immunosuppression when stimulated by phytohemagglutinin but not the other two mitogens tested (Figure 3).

The lymphocyte subpopulation which exhibited the most pronounced changes and which also corresponded with the severity of infection was formed by the CD3 CD19 double negative lymphocytes (Table 2 and Figure $4)$. The numbers of these cells decreased in the spleens of mice which would normally go on to succumb to the 

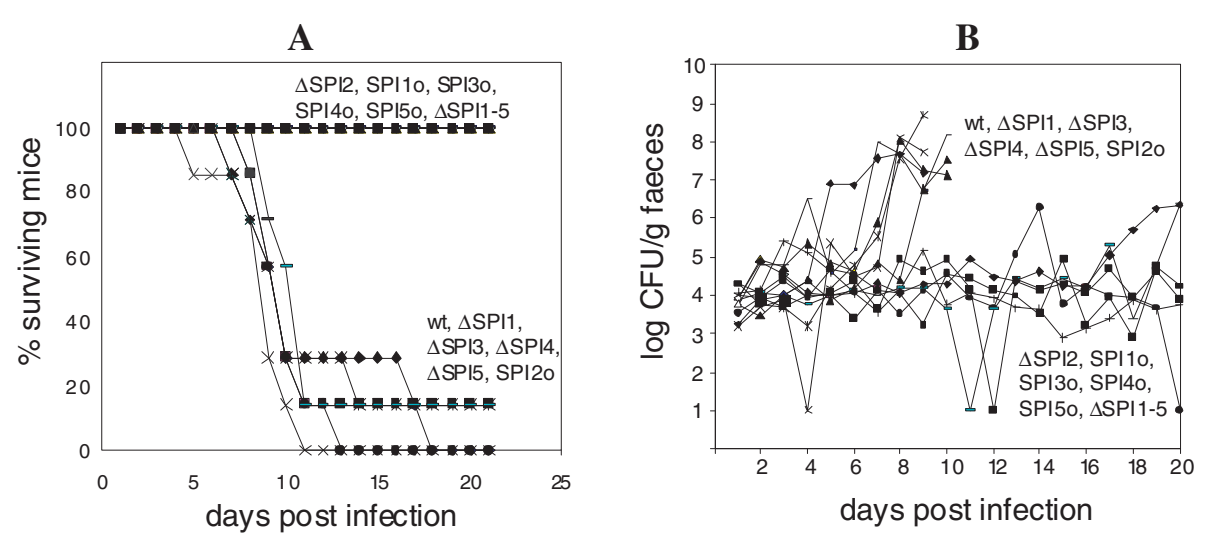

Figure 1 Death rates (panel A) and faecal shedding (panel B) in mice orally infected with S. Enteritidis and SPI mutants. Mice infected with SPI-2 positive mutants exhibited high faecal shedding and died within 3 weeks post-infection. Faecal shedding of individual mice which survived the infection with $\triangle \mathrm{SPI}, \triangle \mathrm{SPI} 4$ and SPI20 (i.e. SPI-2 positive mutants) beyond day 10 is not shown for clarity. Survival rates of the mice infected with $\triangle \mathrm{SPI}, \triangle \mathrm{SPI} 1-5$ and SPI10, SPI30, SPI40 and SPI50 were significantly different from those infected with the wild type S. Enteritidis as determined by Logrank test at $\mathrm{P}<0.01$.

Table 1 Counts of S. Enteritidis in liver, spleen and caecum 5 days post oral infection.

\begin{tabular}{llcl}
\hline & liver & $\begin{array}{c}\text { spleen } \\
\text { (log CFU/g of tissue) }\end{array}$ \\
\hline wt & $4.97 \pm 2.22$ & $5.52 \pm 2.47$ & $4.19 \pm 2.49$ \\
$\Delta$ SPI1 & $5.10 \pm 1.12$ & $5.79 \pm 1.07$ & $4.18 \pm 1.15$ \\
$\Delta$ SPI2 & $0.25 \pm 0.43^{*}$ & $0.56 \pm 0.50^{*}$ & $2.05 \pm 1.49$ \\
$\Delta$ SPI3 & $5.13 \pm 0.19$ & $6.19 \pm 0.36$ & $3.79 \pm 0.02$ \\
$\Delta$ SPI4 & $4.83 \pm 1.42$ & $5.60 \pm 1.36$ & $2.97 \pm 1.75$ \\
$\Delta$ SPI5 & $3.52 \pm 1.79$ & $4.29 \pm 2.32$ & $2.90 \pm 1.40$ \\
SPI10 & $0.33 \pm 0.47^{*}$ & $0.33 \pm 0.47^{*}$ & $2.20 \pm 1.59$ \\
SPI20 & $5.29 \pm 0.87$ & $5.82 \pm 1.07$ & $3.76 \pm 0.77$ \\
SPI30 & $0.00 \pm 0.00^{*}$ & $0.00 \pm 0.00^{*}$ & $0.33 \pm 0.47^{*}$ \\
SPI40 & $0.00 \pm 0.00^{*}$ & $0.00 \pm 0.00^{*}$ & $1.68 \pm 2.38$ \\
SPI50 & $0.00 \pm 0.00^{*}$ & $0.00 \pm 0.00^{*}$ & $1.07 \pm 1.51^{*}$ \\
$\Delta$ SPI1-5 & $0.00 \pm 0.00^{*}$ & $0.00 \pm 0.00^{*}$ & $1.06 \pm 1.50^{*}$ \\
\hline
\end{tabular}

* T-test different at $\mathrm{P}<0.01$ from the mice infected with the wild type S. Enteritidis

infection i.e. in mice infected with the wild type $S$. Enteritidis or any mutant with an intact SPI-2. The CD3 CD19 double negative lymphocytes could be formed either by monocytes gated together with the lymphocytes, or the NK cells. To distinguish between these two potential cell populations, additional experiments were performed. In this case, mice were infected only with the wild type $S$. Enteritidis and $\triangle$ SPI2 mutant, and using four-color flow cytometry CD19, CD3 double negative lymphocytes were further characterised according to the presence or absence of CD14 and CD16. The dominant part of the CD3 CD19 double negative population constituted of CD16+ CD14- cells and these were the cells which decreased after the infection with virulent $S$. Enteritidis. Since CD3 CD14 CD19 negativity and CD16 positivity is characteristic for the NK cells, we concluded that the infection with the wild type strain or any mutant of $S$. Enteritidis with functional SPI-2 resulted in the depletion of NK cells in spleen (Figure 5).

Next we investigated whether the depletion of NK cells was associated specifically with the presence of SPI-2 or whether it was rather a general indicator of $S$. Enteritidis virulence. In this experiment we infected mice with another two attenuated mutants with defects in lon or $r f a L$ and monitored NK cells in the spleen of infected mice. As shown in Figure 6, the NK cells decreased in the spleen only after the infection with the wild type $S$. Enteritidis, but not after the infection with the $r f a L$ or lon mutants.

Although it was obvious that the NK cells decreased after infection with the wild type strain or virulent mutants, the reason for the NK cell depletion was unknown. We considered two alternative hypotheses either the NK cells migrated out of the spleen possibly to the intestinal tract or they died as a result of the extensive killing of $S$. Enteritidis-positive splenocytes. To test these hypotheses, we performed two additional experiments. In the first experiment we analysed cytokine signaling in the intestinal tract of the infected mice and in the second experiment we determined NK cell counts not only in the spleen but also in blood and the caecal lamina propria. These experiments were performed only with the wild type $S$. Enteritidis and $\Delta$ SPI2 mutant.

When the cytokine signaling in the ceacal samples was determined, we did not find any differences in the expression of IFN $\gamma$, iNOS and IL-12p40. Numerically low, but statistically significant induction of TNF $\alpha$ was observed in caecum of mice infected with the wild type $S$. Enteritidis. Mice also responded to $S$. Enteritidis 


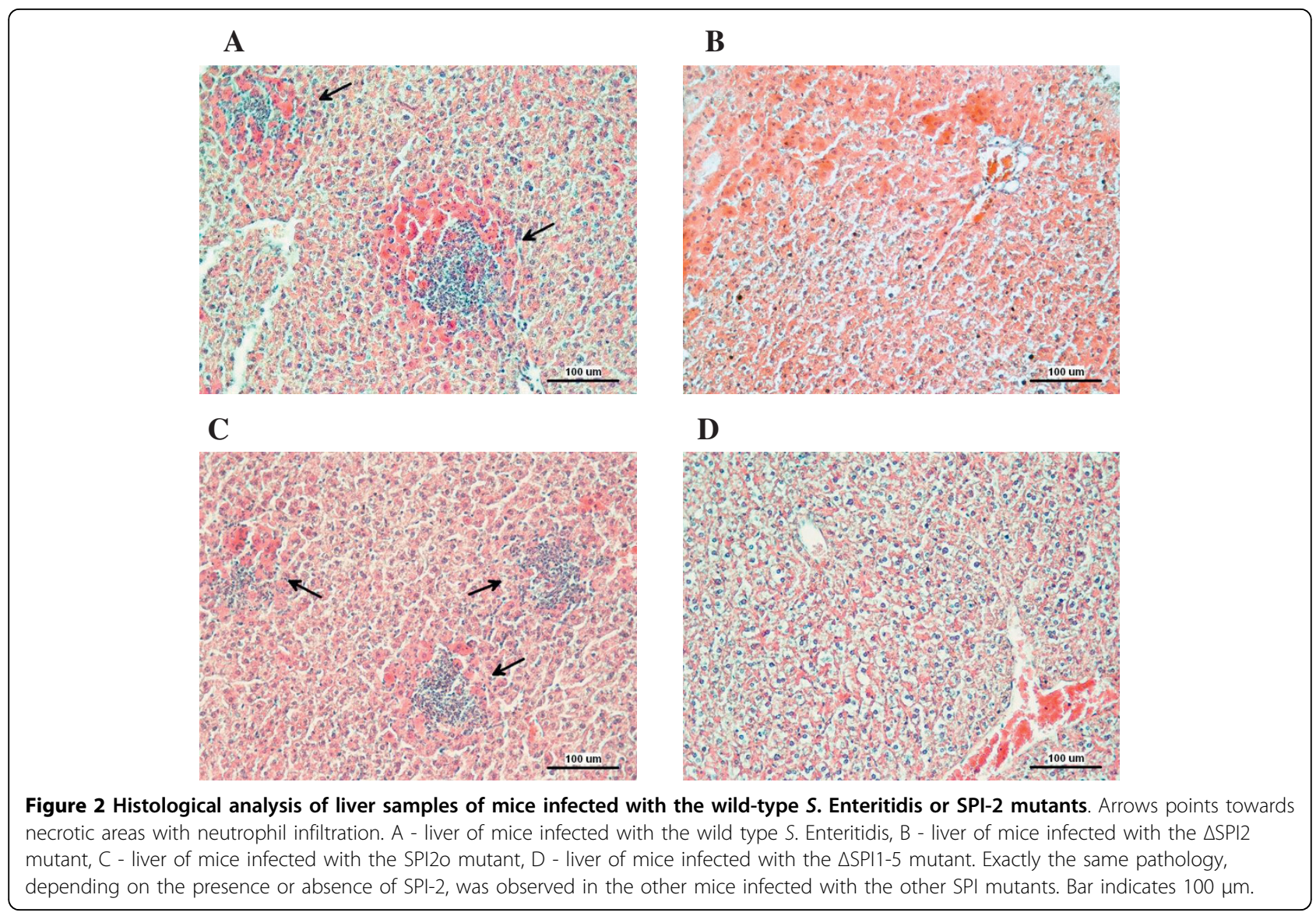

Table 2 Two-colour flow cytometry of splenic CD3 and CD19 T- and B-lymphocytes, CD4 and CD8 T-lymphocytes, and $\gamma \delta$ T-lymphocytes in mice infected with $S$. Enteritidis 5 days post-infection.

\begin{tabular}{llllllll}
\hline & CD3+19- & CD19+3- & CD19-3- & CD4+8+ & CD4+8- & CD4-8+ & $\boldsymbol{\gamma} \boldsymbol{\delta}$ T \\
\hline wt & $52.5 \pm 0.76$ & $41.8 \pm 2.07$ & $5.4 \pm 1.33^{*}$ & $1.4 \pm 0.33$ & $31.1 \pm 2.93$ & $14.8 \pm 0.28$ & $0.93 \pm 0.09$ \\
$\Delta$ SPI1 & $57.1 \pm 6.50$ & $39.6 \pm 5.80$ & $3.2 \pm 0.98^{*}$ & $0.9 \pm 0.10$ & $24.5 \pm 6.26^{*}$ & $16.2 \pm 2.05$ & $0.50 \pm 0.08$ \\
$\Delta$ SPI2 & $50.3 \pm 3.77$ & $41.8 \pm 2.91$ & $7.7 \pm 0.98$ & $1.1 \pm 0.13$ & $27.4 \pm 1.80$ & $14.5 \pm 0.35$ & $0.80 \pm 0.22$ \\
$\Delta$ SPI3 & $55.1 \pm 3.26$ & $40.9 \pm 4.37$ & $3.9 \pm 1.59^{*}$ & $1.4 \pm 0.33$ & $27.1 \pm 4.63$ & $16.4 \pm 1.19$ & $0.53 \pm 0.05$ \\
$\Delta$ SPI4 & $56.5 \pm 4.24$ & $39.5 \pm 3.61$ & $4.1 \pm 1.42^{*}$ & $1.3 \pm 0.46$ & $26.8 \pm 2.80$ & $16.2 \pm 1.05$ & $0.67 \pm 0.24$ \\
$\Delta$ SPI5 & $60.1 \pm 5.22$ & $35.8 \pm 4.05$ & $3.9 \pm 1.25^{*}$ & $1.1 \pm 0.21$ & $33.8 \pm 1.01$ & $14.9 \pm 1.33$ & $0.57 \pm 0.05$ \\
$\Delta$ SPI1-5 & $55.5 \pm 3.07$ & $36.4 \pm 2.86$ & $8.0 \pm 1.79$ & $2.1 \pm 0.41$ & $34.6 \pm 3.01$ & $17.2 \pm 0.26$ & $0.70 \pm 0.08$ \\
SPI1 only & $55.6 \pm 3.78$ & $37.4 \pm 2.54$ & $7.1 \pm 1.75$ & $0.9 \pm 0.26$ & $35.0 \pm 3.44$ & $16.1 \pm 0.70$ & $0.97 \pm 0.05$ \\
SPI2 only & $43.0 \pm 2.50$ & $49.0 \pm 6.63$ & $3.8 \pm 2.02^{*}$ & $0.6 \pm 0.25$ & $23.8 \pm 5.80^{*}$ & $14.4 \pm 1.16$ & $0.80 \pm 0.22$ \\
SPI3 only & $62.7 \pm 4.28$ & $29.9 \pm 4.46$ & $7.5 \pm 0.49$ & $1.4 \pm 0.05$ & $29.2 \pm 2.92$ & $18.6 \pm 0.87$ & $0.80 \pm 0.16$ \\
SPI4 only & $64.2 \pm 4.33$ & $28.9 \pm 3.60$ & $7.0 \pm 0.72$ & $1.6 \pm 0.38$ & $33.6 \pm 4.07$ & $18.9 \pm 1.94$ & $0.73 \pm 0.05$ \\
SPI5 only & $57.8 \pm 0.99$ & $35.5 \pm 1.54$ & $6.7 \pm 1.04$ & $1.4 \pm 0.01$ & $34.6 \pm 0.49$ & $17.0 \pm 1.11$ & $1.07 \pm 0.05$ \\
non infect & $53.0 \pm 10.00$ & $39.2 \pm 10.54$ & $7.7 \pm 1.12$ & $1.2 \pm 0.44$ & $33.7 \pm 6.01$ & $14.4 \pm 2.55$ & $1.01 \pm 0.32$ \\
\hline
\end{tabular}

Numbers show average percentage \pm standard deviation out of total CD45 positive lymphocytes. ${ }^{*}$ T-test different at $P<0.05$ from the non-infected mice, ${ }^{{ }^{8}} \mathrm{P}=0.0634$.

infection by the upregulation of IL-18 although this cytokine was significantly upregulated in mice infected both by the wild type $S$. Enteritidis and the $\Delta$ SPI2 mutant (Figure 7).

Finally we tested whether the depletion of NK cells could be caused by their migration to the caecal lamina propria. We therefore infected mice with wild type $S$. Enteritidis and $\triangle$ SPI2 mutant, and besides the spleen we also determined the counts of the NK cells in blood and the lamina propria. In blood, a significant decrease in NK cells post wild-type $S$. Enteritidis infection was observed. In the lamina propria, the numerical increase 


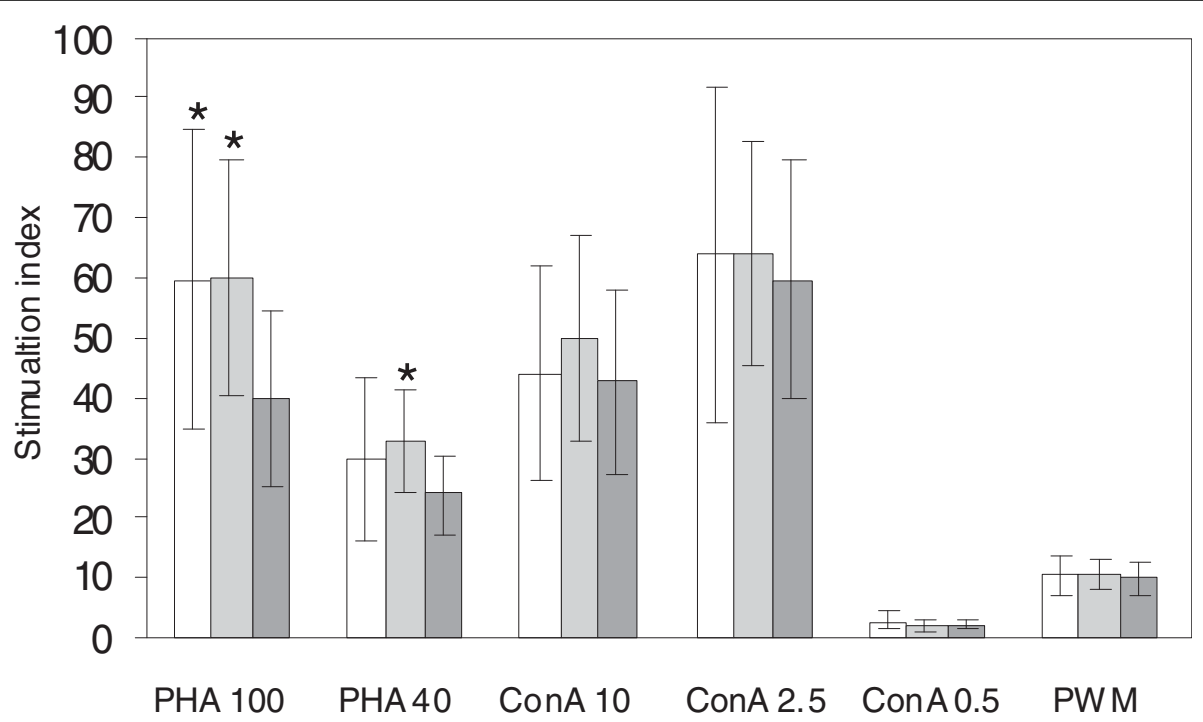

Figure 3 Lymphocyte proliferation assay from non-infected mice (white columns), and mice infected with SPI2-negative (light grey columns) and SPI2-positive (dark grey columns) S. Enteritidis mutants after the stimulation with different concentrations of phytohaemagglutinin (PHA), concanavalin A (ConA) or pokeweed mitogen (PWM). * - t-test different from the mice infected with the SPI-2 positive $S$. Enteritidis at $\mathrm{P}<0.05$.

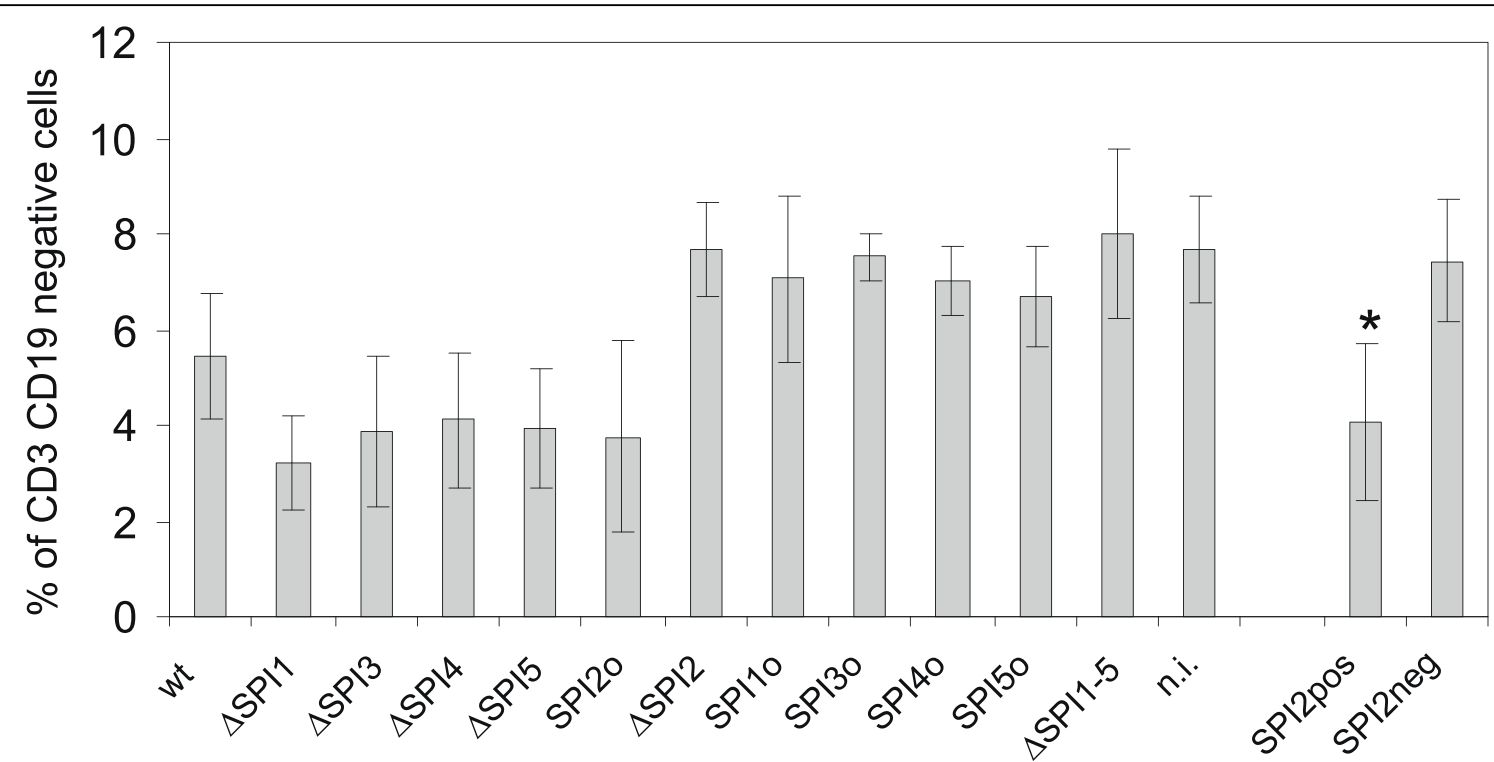

Figure 4 CD3 CD19 double-negative lymphocytes in spleens of mice infected with S. Enteritidis SPI mutants; n.i. - non-infected mice The Y-axis shows percentage of CD3 CD19 double-negative lymphocytes out of total CD45 positive splenic lymphocytes. Columns SPI2pos and SPI2neg show average values for all mice clustered into two groups according to being infected with either any of the SPI-2 positive or the SPI-2 negative mutants. ${ }^{*}$ - t-test different from SPI2neg at $\mathrm{P}<0.01$.

in NK cells was observed although this increase did not reach statistical significance (Figure 8 ).

\section{Discussion}

Similar to the observations of others, progress of the infection in mice, characterised by fecal shedding, fatalities, liver and spleen colonisation and liver injury, was dependent on the presence of SPI-2 but not any other SPI $[3,17,18]$. The exclusivity of SPI-2 dependence for $S$. Enteritidis virulence for mice was such that even in the absence of all remaining SPIs, i.e. in the case of SPI2o mutant, this mutant was capable of causing typhoid similar to that caused by the wild-type strain. This observation was slightly unexpected for the mutants 


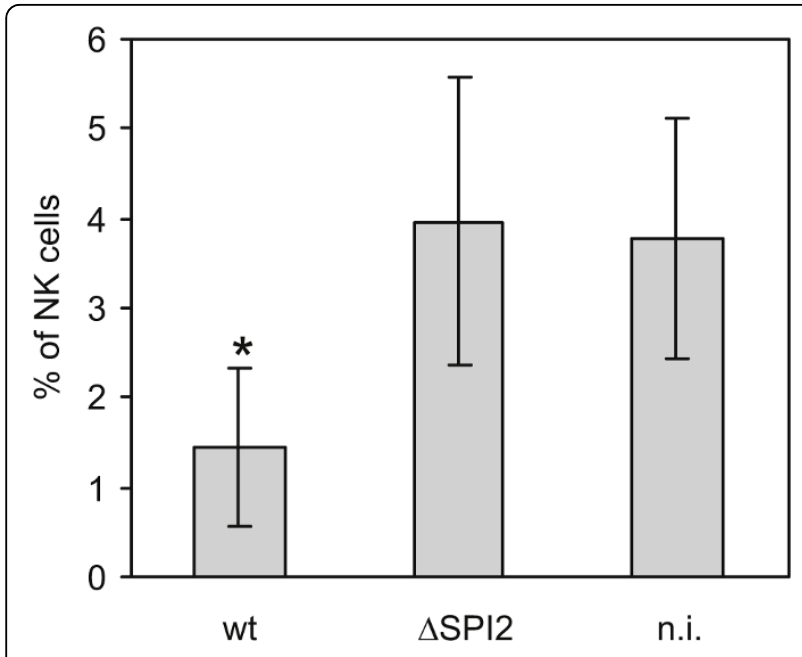

Figure 5 Presence of NK cells in spleen of mice 5 days post infection with the wild type $S$. Enteritidis (wt) or $\triangle$ SPI2 mutant averaged from the animal infections 2,3 and 4 . n.i. - noninfected mice. ${ }^{*}$ - t-test different from the non-infected or $\triangle S P I 2$ mutant infected mice at $P<0.01$.

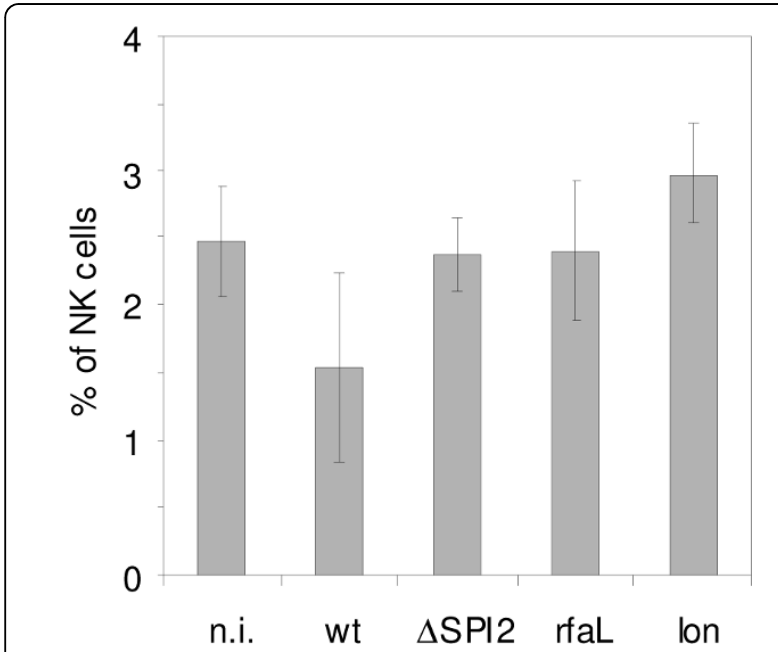

Figure 6 Presence of NK cells in spleen of mice 5 days post infection with the wild type $S$. Enteritidis (wt) or attenuated $\Delta \mathrm{SPI}$, rfaL or lon mutants as determined in the animal infection 2. n.i. - non-infected mice. The NK cells depletion was not specific for the $\triangle S P I 2$ mutant but was a general indicator of the mutant's virulence or avirulence. Since there were only 3 animals per group and greater variation was observed among the mice infected with the wild type $S$. Enteritidis, none of the differences in this experiment reached statistical significance.

without SPI-1. However Murray and Lee already reported on minimal influence of the removal of the whole SPI-1 on the virulence of $S$. Typhimurium for Balb/C mice [18] and also single gene mutants in $\operatorname{sop} B$, sopD or sipA were only weakly attenuated $[19,20]$ or the attenuation was expressed only as a minor delay in mean time to death [21]. In addition, dose dependent difference in the virulence of $\operatorname{sop} B$ mutant of $S$. Typhimurium was described [20] and since we used only a single dose corresponding to $100 \times \mathrm{LD}_{50}$, minor phenotypic differences associated with the presence or absence of SPI-1 could remain undetected.

The infection did not influence the counts of $\mathrm{T}$ - and B-lymphocytes in the spleen at the time of sampling, similarly to the findings of Geddes et al [12]. We did not even observe an increase in $\gamma \delta \mathrm{T}$-lymphocytes although these were reported to increase in mice after infection with a virulence plasmid-cured derivative of $S$. Choleraesuis [22]. Although there were no changes in these cell populations, general immunosuppression has been observed when PHA was used as the mitogen for stimulation. Since the immunosuppression was not observed when ConA and PHW were used for the stimulation, it can be expected that the population which was primarily immunosuppressed was that represented by the CD4 Th lymphocytes [23].

The most significant changes correlating with the severity of infection were observed in NK cells that could result in the reduced production of pro-inflammatory IFN $\gamma[24,25]$ and immunosuppressive IL-10 [26]. The decrease in NK cells in systemic sites may result also in a decrease in Th1 polarisation of the immune response [27] followed by mice fatalities. The depletion of NK cells in mice after the infection with wild-type Salmonella has been previously described [16]. However, whether the virulence mechanisms encoded by any of the pathogenicity islands are involved in this response has never been addressed. Our results indicate that there is no direct correlation between the presence of any of the SPIs and the NK cell depletion. Although the decrease in NK cell counts was not observed in all mice infected with SPI2-negative $S$. Enteritidis, it was also not observed in mice infected with the attenuated $S$. Enteritidis mutants defective in lon or $r f a L$. The depletion of NK cells therefore does not appear to be directly influenced by the SPI- 2 encoded type III secretion system and instead, it seems to be a general indicator of virulence or attenuation of a mutant for mice.

Finally we considered whether the depletion of NK cells in spleen was caused by the migration of these cells from the spleen to other tissues such as those in the intestinal tract since the accumulation of NK cell in the intestinal tract, although in a slightly different model of streptomycin-treated mice, has been reported [24]. The decrease of NK cells in spleen and circulation together with a minor increase of NK cells in caecum (Figure 8) would support the hypothesis on migration. However, because the NK cell increase in the lamina propria as well as the cytokine response in caecum was numerically similar in mice infected with the wild-type $S$. Enteritidis and the $\triangle \mathrm{SPI} 2$ mutant, while the NK cell 


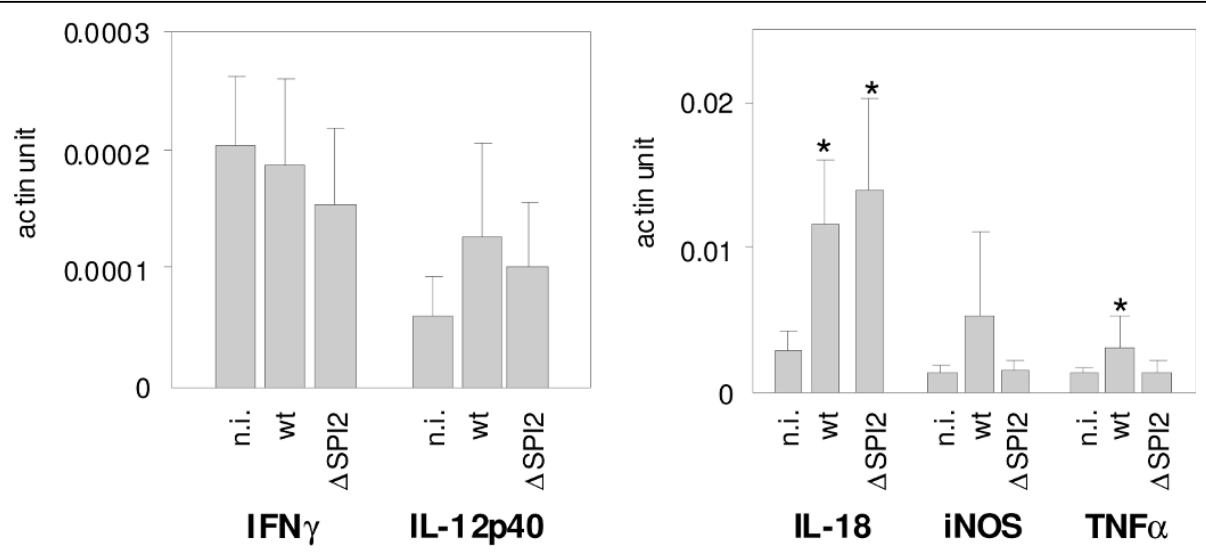

Figure 7 Cytokine response in caecum of mice infected with the wild type $S$. Enteritidis (wt) and $\Delta S P I 2$ mutant. n.i. - non-infected mice. * - t-test different from the non-infected mice at $P<0.05$.

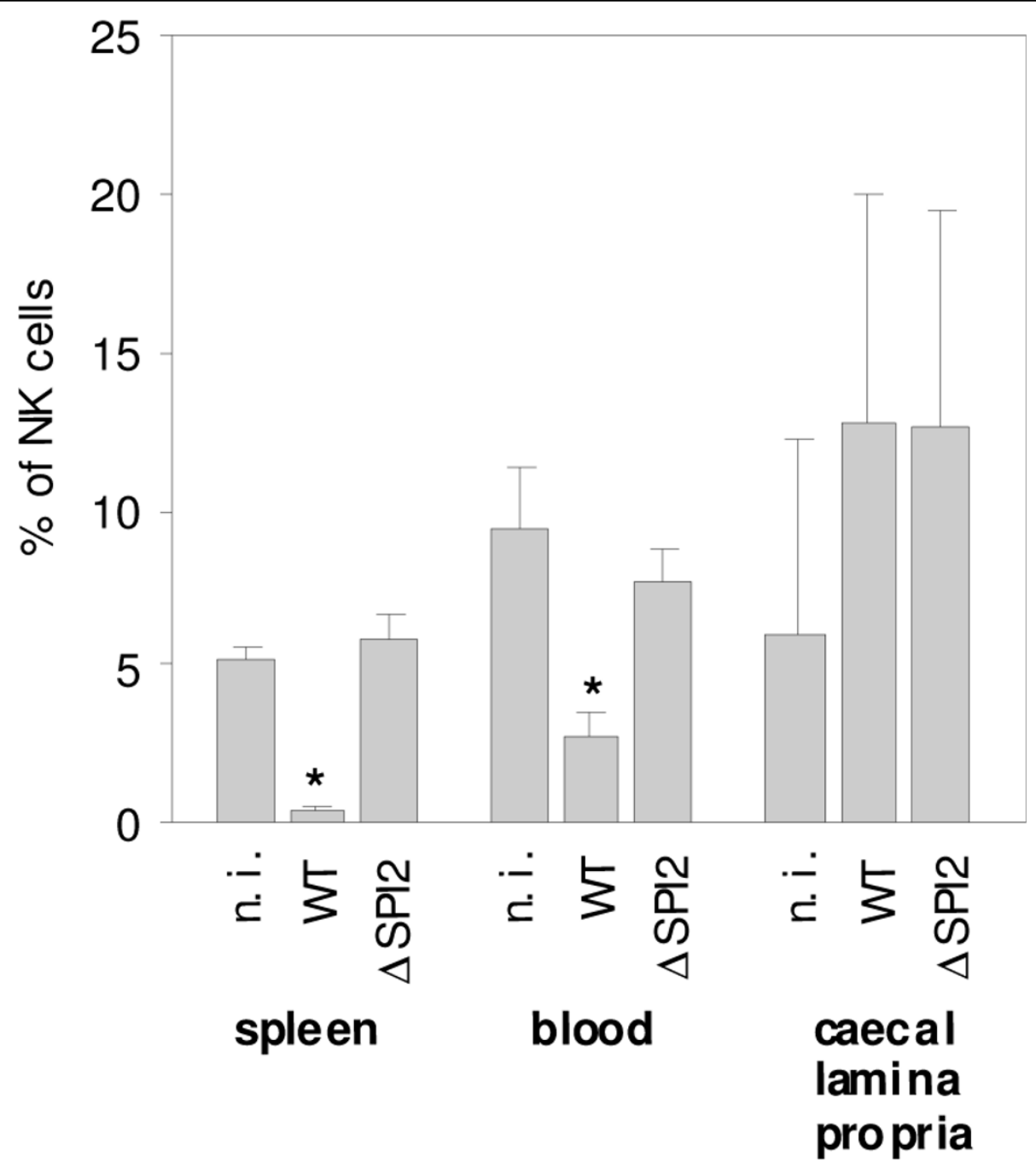

Figure 8 Distribution of NK cells in spleen, blood and caecal lamina propria of mice infected with the wild type S. Enteritidis (wt) and $\Delta$ SPI2 mutant as determined in the animal infection 4. n.i. - non-infected mice. * - t-test different from the non-infected mice at $P<0.01$. 
depletion in spleen and blood occurred only after the infection with the wild type $S$. Enteritidis, the decrease in NK cells in spleen and circulation cannot be directly linked with their migration to caecum.

\section{Conclusions}

In this study we have shown that the virulence of $S$. Enteritidis for Balb/C mice is exclusively dependent on the presence of SPI-2 in its genome, and a major hallmark of the infection in terms of changes in lymphocyte populations is the depletion of NK cells in the spleen and circulating blood. The decrease of NK cells in circulation can be used as a marker of attenuation or virulence of different $S$. Enteritidis mutants for Balb/C mice.

\section{Methods}

\section{Bacterial strains and growth conditions}

$S$. Enteritidis147, a clone resistant to nalidixic acid, was used in this study [28]. Isogenic mutants without individual SPIs (SPI-1 to SPI-5), lon and $r f a L$ mutants are listed in Table 3. SPI mutants were generated by a modified procedure of $\lambda$ Red recombination [29] which we have described previously [30]. Absence of individual SPIs was confirmed by positive PCR using primers flanking individual SPIs and negative PCR using primers specific for the genes localised inside each of the pathogenicity island (not shown). The strains were propagated in $\mathrm{LB}$ broth or $\mathrm{LB}$ agar at $37^{\circ} \mathrm{C}$.

\section{Experimental infection of mice}

In all the experiments, six-week-old Balb/C mice were orally infected with $10^{4} \mathrm{CFU}$ (equivalent to $100 \times \mathrm{LD}_{50}$ of the wild type strain) of the wild type strain or each of the mutants in a volume of $0.1 \mathrm{ml}$ using a gastric gavage without any neutralisation of gastric acid prior the infection. In the first animal infection, 12 groups of 10 mice each were infected with all the SPI mutants and wild type $S$. Enteritidis. A negative control group consisted of 3 uninfected animals. On day 5 post-infection, 3 mice from each group including all non-infected control mice were sacrificed and used for the determination of bacterial counts in liver, spleen and caecum, two-color flow cytometry of splenic lymphocytes, histology in liver and caecum, and lymphocyte proliferation assay. The remaining 7 mice were left for monitoring of feacal shedding and mortalities until day 21 post infection when the experiment was terminated. Faecal shedding was monitored on a daily basis by transferring the mice into a clean plastic box and collecting pooled fresh droppings 30 minutes later. Bacterial counts in liver, spleen, caecal content and faecal droppings were determined using a standard plating method described previously [31]. For the purposes of statistical analysis, a viable count of $\log _{10}<2.5$ (limit for direct plate detection) obtained from a sample positive only after enrichment was rated as $\log _{10}=1.0$ whereas samples negative for $S$. Enteritidis after enrichment were rated as $\log _{10}=$ 0 . During the post mortem analysis, liver and caecal samples were also taken for histological examinations. The samples were fixed in $10 \%$ neutral buffered formalin for $24 \mathrm{~h}$, embedded in paraffin wax, sectioned at $5 \mu \mathrm{m}$, and stained with haematoxylin-eosin.

In the second animal infection, 3 mice per group, including 3 non-infected mice, were infected with the wild-type $S$. Enteritidis, or with $\triangle \mathrm{SPI} 2$, lon or $r f a L$ mutants. In this experiment, four-colour flow cytometry detecting CD3, CD19, CD14 and CD16 in splenic lymphocytes was performed.

In the third animal infection, 5 mice per group, including 5 non-infected mice, were infected with the wild type $S$. Enteritidis or $\triangle \mathrm{SPI} 2$ mutant. In this experiment, four-colour flow cytometry detecting CD3, CD19,

Table 3 List of strains used in this study.

\begin{tabular}{|c|c|c|c|c|}
\hline strain & strain ID & SPI present & SPI absent & reference \\
\hline S. Enteritidis $147 \mathrm{Nal}$ wild type & 7F4 & $1,2,3,4,5$ & none & {$[28]$} \\
\hline S. Enteritidis $147 \mathrm{Nal} \Delta \mathrm{SPI} 1$ & $4 \mathrm{~A} 10$ & $2,3,4,5$ & 1 & {$[30]$} \\
\hline S. Enteritidis $147 \mathrm{Nal} \triangle \mathrm{SPI} 2$ & $5 \mathrm{D} 10$ & $1,3,4,5$ & 2 & {$[30]$} \\
\hline S. Enteritidis $147 \mathrm{Nal} \triangle \mathrm{SPI} 3$ & $6 \mathrm{~A} 9$ & $1,2,4,5$ & 3 & {$[30]$} \\
\hline S. Enteritidis $147 \mathrm{Nal} \Delta \mathrm{SPI} 4$ & $4 \mathrm{~B} 10$ & $1,2,3,5$ & 4 & {$[30]$} \\
\hline S. Enteritidis $147 \mathrm{Nal} \triangle \mathrm{SPI} 5$ & $4 J 1$ & $1,2,3,4$ & 5 & {$[30]$} \\
\hline S. Enteritidis $147 \mathrm{Nal} \Delta \mathrm{SPI} 1-5$ & 5E9 & none & $1,2,3,4,5$ & {$[30]$} \\
\hline S. Enteritidis $147 \mathrm{Nal}$ SPI10 & $5 G 10$ & 1 & $2,3,4,5$ & {$[30]$} \\
\hline S. Enteritidis $147 \mathrm{Nal}$ SPI20 & $5 \mathrm{H} 9$ & 2 & $1,3,4,5$ & {$[30]$} \\
\hline S. Enteritidis $147 \mathrm{Nal}$ SPI3O & $5 J 10$ & 3 & $1,2,4,5$ & {$[30]$} \\
\hline S. Enteritidis $147 \mathrm{Nal}$ SPI40 & $5 \mathrm{D} 9$ & 4 & $1,2,3,5$ & {$[30]$} \\
\hline S. Enteritidis $147 \mathrm{Nal}$ SPI50 & $5 \mathrm{H} 10$ & 5 & $1,2,3,4$ & {$[30]$} \\
\hline S. Enteritidis $147 \mathrm{Nal} \Delta$ lon & $16 \mathrm{H} 2$ & $1,2,3,4,5$ & none & {$[33]$} \\
\hline S. Enteritidis $147 \mathrm{Nal} \Delta \mathrm{rfaL}$ & $14 \mathrm{E} 5$ & $1,2,3,4,5$ & none & [33] \\
\hline
\end{tabular}


CD14 and CD16 in splenic lymphocytes was repeated and in addition, cytokine signaling in caecum has been determined by RT PCR.

In the fourth animal infection, 5 mice per group, including 5 non-infected mice, were infected with the wild type $S$. Enteritidis and $\triangle$ SPI2 mutant, and four-colour flow cytometry detecting CD3, CD19, CD14 and CD16 cells in lymphocytes from spleen, blood and caecal lamina propria was performed.

All the animal infections were performed according to the relevant national legislation and were approved and supervised by the institutional Ethics Committee on Animal Experiments followed by the approval of the Animal Welfare Committee at the Ministry of Agriculture of the Czech Republic.

\section{Lymphocyte proliferation assay}

The proliferation activity of lymphocytes was determined using the mitogen-driven proliferation assay. Spleen tissues were collected into RPMI 1640 medium (Sigma, St. Louis, USA) and cell suspensions were prepared by pressing the tissue through a fine nylon mesh. After ammonium chloride-mediated lysis of erythrocytes, the density of the suspension was adjusted to $10^{6}$ per ml of RPMI 1640 medium supplemented with $10 \%$ pre-colostral calf serum, $100000 \mathrm{U} / \mathrm{l}$ penicillin and 0.2 $\mathrm{g} / \mathrm{l}$ streptomycin. Two hundred microliters of the cell suspension were transferred in triplicate into the wells of a 96-well flat-bottomed microtitre plate. Mitogens were used as follow: phytohaemagglutinin (PHA) at the concentrations $100 \mu \mathrm{g} / \mathrm{ml}$ and $40 \mu \mathrm{g} / \mathrm{ml}$, concanavalin A (ConA) at the concentrations $10 \mu \mathrm{g} / \mathrm{ml}, 2.5 \mu \mathrm{g} / \mathrm{ml}$, and $0.5 \mu \mathrm{g} / \mathrm{ml}$, and pokeweed mitogen (PWM) at the concentration $10 \mu \mathrm{g} / \mathrm{ml}$. Lymphocytes incubated in the absence of these mitogens served as non-stimulated controls. The microplates were incubated at $37^{\circ} \mathrm{C}$ under the $5 \% \mathrm{CO}_{2}$ atmosphere for 3 days, and 20 hours before harvesting (FilterMate Harvestor, Packard Bioscience Instrument Company), $50 \mu \mathrm{l}$ of medium with ${ }^{3} \mathrm{H}$-thymidine $(5 \mu \mathrm{Ci} / \mathrm{ml})$ was added. The incorporation of ${ }^{3} \mathrm{H}$ thymidine was analyzed by a microplate scintillation and luminescence counter (TopCount $\mathrm{NXT}^{\mathrm{T} \mathrm{m}}$, Packard Bioscience Instrument Company). The results were expressed as stimulation indices, which have been calculated as the ratio of counts per minute in stimulated samples and non-stimulated controls.

\section{Flow cytometry}

For the flow cytometry, splenic lymphocytes were purified as described above. Lymphocytes from blood were isolated by the whole-blood lysis technique as described previously [32]. To isolate lymphocytes from gut tissue, the tissue was incubated in HBSS-2 containing $2 \mathrm{mM}$ $\mathrm{DTT}$ and $0.5 \mathrm{mM}$ EDTA at $37^{\circ} \mathrm{C}$ for $40 \mathrm{~min}$ followed by collagenase type IV $(50 \mathrm{U} / \mathrm{ml})$ treatment for additional $90 \mathrm{~min}$. The lymphocytes were finally isolated from cell suspensions by a gradient centrifugation with $80 \%$ Percol.

In the next step, the cells were washed in PBS with $0.2 \%$ gelatin from cold water fish skin, $0.1 \%$ sodium azide and $0.05 \mathrm{mM}$ EDTA and resuspended in the same buffer to a density of $5 \times 10^{6}$ cells $/ \mathrm{ml}$. The following anti-mouse monoclonal antibodies directed against surface antigens were used: TcR1-FITC (clone GL3) from AbD Serotec and CD19-PE-Cy5.5 (clone 6D5), CD3APC (clone 145-2C11), CD45-FITC (clone 30-F11), CD16/32-PE (clone 93) and CD14-FITC (clone Sa2-8) from eBioscience. Before the flow cytometry, the isolated lymphocytes were incubated with the appropriate antibodies for $30 \mathrm{~min}$, washed twice in PBS and analyzed by FACSCalibur $^{\mathrm{TM}}$ (BD Biosciences) equipped with a 488 $\mathrm{nm}$ argon-ion laser and a $633 \mathrm{~nm}$ diode laser. At least $10^{5}$ cells were analyzed and data analyses of gated lymphocytes positive for CD45 were performed using CELLQuest ${ }^{\mathrm{TM}}$ Pro software (BD Biosciences). $\gamma \delta$ T-lymphocytes were identified in a single TcR-specific staining. CD19-positive B-lymphocytes and CD3-positive Tlymphocytes, and CD4 and CD8 Th- and Tc-lymphocytes, were each characterized by separate two-colour analysis. Finally, the CD14 and CD16 positive cells out of CD3 and CD19 double negative were quantified using a four-colour analysis.

\section{Real time PCR}

Total RNA was extracted from caecal wall samples using the RNeasy Lipid Tissue Kit (Qiagen). Resulting RNA was eluted with $50 \mu \mathrm{l}$ RNase-free water and used immediately in reverse transcription using $M-M L V$ reverse transcriptase (Invitrogen) and oligo-T primers. The resulting cDNA was purified by the QiaPrep PCR Purification kit (Qiagen) and used as a template for quantitative PCR. mRNA expression rates of TNF $\alpha$, IL-12p40, IL-18, IFN $\gamma$ and iNOS were determined using the QuantiTect $^{\mathrm{TM}}$ SYBR $^{\odot}$ Green RT-PCR Kit (Qiagen) with $\beta$-actin mRNA as a reference. Primers used for the RT-PCR are listed in Table 4. The threshold cycle values $(\mathrm{Ct})$ of gene of interest were first normalised to the $\mathrm{Ct}$ value of actin reference mRNA $(\Delta \mathrm{Ct})$ and the normalised mRNA levels were calculated as $2^{(-\Delta C t)}$. The normalised mRNA levels of a particular cytokine were then used for t-test comparisons between the infected and non-infected animals and are also given in figures as "actin" units.

\section{Statistical analysis}

Data were evaluated by parametric two-sample, equal variance, t-test and non-parametric Mann-Whitney test comparing the experimental groups either to the noninfected control mice or to the mice infected with the 
Table 4 List of primers used for the quantification of gene expression by real time RT PCR.

\begin{tabular}{|c|c|c|c|}
\hline primer & sequence $5^{\prime}-3^{\prime}$ & length (bp) & Reference \\
\hline TNF $\alpha$ For & CATCTTCTCAAAATTCGAGTGACAA & 175 & {$[34]$} \\
\hline TNF $\alpha$ Rev & TGGGAGTAGACAAGGTACAACCC & & \\
\hline IL-12p40For & GGAAGCACGGCAGCAGAATA & 180 & [34] \\
\hline IL-12p40Rev & AACTTGAGGGAGAAGTAGGAATGG & & \\
\hline IL-18For & CAGGCCTGACATCTTCTGCAA & 105 & [34] \\
\hline IL-18Rev & TCTGACATGGCAGCCATTGT & & \\
\hline IFNyFor & AACAGCAAGGCGAAAAAGGA & 92 & this study \\
\hline IFNyRev & GTGGACCACTCGGATGAGC & & \\
\hline iNOSFor & CAGCTGGGCTGTACAAACCTT & 95 & [34] \\
\hline iNOSRev & CATTGGAAGTGAAGCGTTTCG & & \\
\hline$\beta$-actinFor & CTTTGCAGCTCCTTCGTTG & 150 & this study \\
\hline$\beta$-actinRev & ACGATGGAGGGGAATACAGC & & \\
\hline
\end{tabular}

wild type $S$. Enteritidis. Survival rates were analysed using Logrank test. Minor differences in the results of $t$ test and Mann-Whitney test were recorded only during the analysis of data presented in Table 2 in CD4 and CD8 T-lymphocytes, and $\gamma \delta \mathrm{T}$-lymphocytes. All remaining significant differences were identically confirmed by both these tests and in figures we therefore refer only to the results of the t-test. In all the tables and figures, the average values of the individual animals \pm standard deviation are shown. In some of the data analyses we clustered the mutants according to the presence of SPI2 in their genome. All the statistical calculations have been performed using Prisma statistical software.

\section{Acknowledgements}

This work was supported by project MZE0002716202 of the Ministry of Agriculture of the Czech Republic, AdmireVet project CZ.1.05/2.1.00/01.0006 from the Czech Ministry of Education and project 524/09/0215 of the Czech Science Foundation. The authors wish to acknowledge an excellent technical assistance of Michaela Dekanova and Prof. P.A. Barrow, University of Nottingham, UK, for English language corrections.

\section{Authors' contributions}

DK and AS constructed the SPI mutants, FS and $\mathrm{HH}$ were responsible for the animal experiments. VK performed the histology and JV determined the cytokine expression by RT PCR. MF and PO were responsible for the flow cytometry. IR designed the studies and wrote the manuscript. All authors read and approved the final manuscript.

Received: 29 July 2009 Accepted: 12 March 2010 Published: 12 March 2010

\section{References}

1. Mills DM, Bajaj $\mathrm{V}$, Lee CA: A 40 kb chromosomal fragment encoding Salmonella typhimurium invasion genes is absent from the corresponding region of the Escherichia coli K-12 chromosome. $\mathrm{Mol}$ Microbiol 1995, 15:749-759.

2. Bajaj V, Lucas RL, Hwang C, Lee CA: Co-ordinate regulation of Salmonella typhimurium invasion genes by environmental and regulatory factors is mediated by control of hilA expression. Mol Microbiol 1996, 22:703-714.

3. Cirillo DM, Valdivia RH, Monack DM, Falkow S: Macrophage-dependent induction of the Salmonella pathogenicity island 2 type III secretion system and its role in intracellular survival. Mol Microbiol 1998, 30:175-188.
4. Blanc-Potard AB, Groisman EA: The Salmonella selC locus contains a pathogenicity island mediating intramacrophage survival. EMBO J 1997, 16:5376-5385.

5. Morgan E, Campbell JD, Rowe SC, Bispham J, Stevens MP, Bowen AJ, Barrow PA, Maskell DJ, Wallis TS: Identification of host-specific colonization factors of Salmonella enterica serovar Typhimurium. Mol Microbiol 2004, 54:994-1010.

6. Kiss T, Morgan E, Nagy G: Contribution of SPI-4 genes to the virulence of Salmonella enterica. FEMS Microbiol Lett 2007, 275:153-159.

7. Knodler LA, Celli J, Hardt WD, Vallance BA, Yip C, Finlay BB: Salmonella effectors within a single pathogenicity island are differentially expressed and translocated by separate type III secretion systems. Mol Microbiol 2002, 43:1089-1103.

8. Papezova K, Gregorova D, Jonuschies J, Rychlik I: Ordered expression of virulence genes in Salmonella enterica serovar typhimurium. Folia Microbiol (Praha) 2007, 52:107-114.

9. Kaiser P, Rothwell L, Galyov EE, Barrow PA, Burnside J, Wigley P: Differential cytokine expression in avian cells in response to invasion by Salmonella typhimurium, Salmonella enteritidis and Salmonella gallinarum. Microbiology 2000, 146(Pt 12):3217-3226.

10. Zhang S, Adams LG, Nunes J, Khare S, Tsolis RM, Baumler AJ: Secreted effector proteins of Salmonella enterica serotype typhimurium elicit host-specific chemokine profiles in animal models of typhoid fever and enterocolitis. Infect Immun 2003, 71:4795-4803.

11. Wigley P, Hulme S, Powers C, Beal R, Smith A, Barrow P: Oral infection with the Salmonella enterica serovar Gallinarum $9 R$ attenuated live vaccine as a model to characterise immunity to fowl typhoid in the chicken. BMC Vet Res 2005, 1:2.

12. Geddes K, Cruz F, Heffron F: Analysis of cells targeted by Salmonella type III secretion in vivo. PLoS Pathog 2007, 3:e196.

13. Hersh D, Monack DM, Smith MR, Ghori N, Falkow S, Zychlinsky A: The Salmonella invasin SipB induces macrophage apoptosis by binding to caspase-1. Proc Natl Acad Sci USA 1999, 96:2396-2401.

14. Lundberg U, Vinatzer U, Berdnik D, von Gabain A, Baccarini M: Growth phase-regulated induction of Salmonella -induced macrophage apoptosis correlates with transient expression of SPI-1 genes. J Bacteriol 1999, 181:3433-3437

15. Halici S, Zenk SF, Jantsch J, Hensel M: Functional analysis of the Salmonella pathogenicity island 2-mediated inhibition of antigen presentation in dendritic cells. Infect Immun 2008, 76:4924-4933.

16. Kirby AC, Yrlid U, Wick MJ: The innate immune response differs in primary and secondary Salmonella infection. J Immunol 2002, 169:4450-4459.

17. Hensel M, Shea JE, Waterman SR, Mundy R, Nikolaus T, Banks G, VazquezTorres A, Gleeson C, Fang FC, Holden DW: Genes encoding putative effector proteins of the type III secretion system of Salmonella pathogenicity island 2 are required for bacterial virulence and proliferation in macrophages. Mol Microbiol 1998, 30:163-174.

18. Murray RA, Lee CA: Invasion genes are not required for Salmonella enterica serovar typhimurium to breach the intestinal epithelium: 
evidence that Salmonella pathogenicity island 1 has alternative functions during infection. Infect Immun 2000, 68:5050-5055.

19. Jiang $X$, Rossanese OW, Brown NF, Kujat-Choy S, Galan JE, Finlay BB, Brumell JH: The related effector proteins SopD and SopD2 from Salmonella enterica serovar Typhimurium contribute to virulence during systemic infection of mice. Mol Microbiol 2004, 54:1186-1198.

20. Pfeifer CG, Marcus SL, Steele-Mortimer O, Knodler LA, Finlay BB: Salmonella typhimurium virulence genes are induced upon bacterial invasion into phagocytic and nonphagocytic cells. Infect Immun 1999, 67:5690-5698.

21. Kaniga K, Trollinger D, Galan JE: Identification of two targets of the type III protein secretion system encoded by the inv and spa loci of Salmonella typhimurium that have homology to the Shigella IpaD and IpaA proteins. J Bacteriol 1995, 177:7078-7085.

22. Emoto M, Naito T, Nakamura R, Yoshikai Y: Different appearance of gamma delta T cells during salmonellosis between Ityr and Itys mice. $J$ Immunol 1993, 150:3411-3420.

23. Grillon C, Monsigny M, Kieda C: Changes in the expression of lectins in human T lymphocyte membrane upon mitogenic stimulation. Carbohydr Res 1991, 213:283-292.

24. Harrington L, Srikanth CV, Antony R, Shi HN, Cherayil BJ: A role for natural killer cells in intestinal inflammation caused by infection with Salmonella enterica serovar Typhimurium. FEMS Immunol Med Microbiol 2007, 51:372-380.

25. Lapaque N, Walzer T, Meresse S, Vivier E, Trowsdale J: Interactions between human NK cells and macrophages in response to Salmonella infection. J Immunol 2009, 182:4339-4348.

26. Perona-Wright G, Mohrs K, Szaba FM, Kummer LW, Madan R, Karp CL, Johnson LL, Smiley ST, Mohrs M: Systemic but not local infections elicit immunosuppressive IL-10 production by natural killer cells. Cell Host Microbe 2009, 6:503-512.

27. Agaugue S, Marcenaro E, Ferranti B, Moretta L, Moretta A: Human natural killer cells exposed to IL-2, IL-12, IL-18, or IL-4 differently modulate priming of naive T cells by monocyte-derived dendritic cells. Blood 2008, 112:1776-1783.

28. Methner U, Barrow PA, Gregorova D, Rychlik I: Intestinal colonisationinhibition and virulence of Salmonella phoP, rpoS and ompC deletion mutants in chickens. Vet Microbiol 2004, 98:37-43.

29. Datsenko KA, Wanner BL: One-step inactivation of chromosomal genes in Escherichia coli K-12 using PCR products. Proc Natl Acad Sci USA 2000, 97:6640-6645.

30. Rychlik I, Karasova D, Sebkova A, Volf J, Sisak F, Havlickova H, Kummer V Imre A, Szmolka A, Nagy B: Virulence potential of five major pathogenicity islands (SPI-1 to SPI-5) of Salmonella enterica serovar Enteritidis for chickens. BMC Microbiol 2009, 9:268.

31. Methner U, al Shabibi S, Meyer H: Experimental oral infection of specific pathogen-free laying hens and cocks with Salmonella enteritidis strains. Zentralbl Veterinarmed B 1995, 42:459-469.

32. Faldyna M, Leva L, Knotigova P, Toman M: Lymphocyte subsets in peripheral blood of dogs-a flow cytometric study. Vet Immunol Immunopathol 2001, 82:23-37.

33. Karasova D, Sebkova A, Vrbas V, Havlickova H, Sisak F, Rychlik I: Comparative analysis of Salmonella enterica serovar Enteritidis mutants with a vaccine potential. Vaccine 2009, 27:5265-5270.

34. Overbergh L, Giulietti A, Valckx D, Decallonne R, Bouillon R, Mathieu C: The use of real-time reverse transcriptase PCR for the quantification of cytokine gene expression. J Biomol Tech 2003, 14:33-43.

doi:10.1186/1471-2180-10-75

Cite this article as: Karasova et al: Influence of 5 major Salmonella pathogenicity islands on NK cell depletion in mice infected with Salmonella enterica serovar Enteritidis. BMC Microbiology 2010 10:75.

\section{Submit your next manuscript to BioMed Central and take full advantage of:}

- Convenient online submission

- Thorough peer review

- No space constraints or color figure charges

- Immediate publication on acceptance

- Inclusion in PubMed, CAS, Scopus and Google Scholar

- Research which is freely available for redistribution

Submit your manuscript at www.biomedcentral.com/submit 